\title{
Hemophagocytic lymphohistiocytosis presenting with annular erythema multiforme-like eruptions in a patient with angioimmunoblastic $T$ cell lymphoma: A case report
}

\author{
LIPING ZHANG ${ }^{1}$, CHUNGUANG TONG $^{2}$, YAQI TAN ${ }^{2}$, SHIGUANG PENG $^{2}$, YANLING HE $^{2}$ and TIANYOU WANG ${ }^{1}$ \\ ${ }^{1}$ Department of Hematology and Oncology, Beijing Children's Hospital, Capital Medical University, Beijing 100045; \\ ${ }^{2}$ Department of Dermatology, Beijing Chao-Yang Hospital, Capital Medical University, Beijing 100020, P.R. China
}

Received December 31, 2017; Accepted June 1, 2018

DOI: $10.3892 /$ etm. 2018.6420

\begin{abstract}
Angioimmunoblastic T cell lymphoma (AITL)associated hemophagocytic lymphohistiocytosis (HLH) rarely occurs with annular erythema multiforme-like rashes. The present case report describes a patient who was misdiagnosed with erythema multiforme at an early stage of the disease due to annular erythema multiforme-like eruptions. However, antihistamine treatment was ineffective. The patient progressed rapidly with high fever, hepatosplenomegaly and pharyngitis. The number of copies of Epstein-Barr virus DNA continuously increased. Accompanied by the swelling of lymph nodes, the blood cell count decreased. Further bone-marrow examination and biopsy of the lymph nodes were conducted. The patient was eventually diagnosed with AITL-associated HLH, and treated with etoposide together with cyclophosphamide, doxorubicin, vincristine and prednisolone. The patient was successfully treated with several courses of chemotherapy. In view of the fact that AITL-associated HLH with annular erythema multiforme-like rashes is relatively rare worldwide and is associated with a high mortality rate, the data on previous cases were reviewed with the hope of providing clinical bases for early diagnosis and treatment of AITL-associated HLH.
\end{abstract}

\section{Introduction}

Hemophagocytic lymphohistiocytosis (HLH), also known as hemophagocytic syndrome, is a rare, life-threatening

Correspondence to: Dr Yanling He, Department of Dermatology, Beijing Chao-Yang Hospital, Capital Medical University, 8 Gongtinan Road, Beijing 100020, P.R. China

E-mail: keepmovingzlp@sina.com

Dr Tianyou Wang, Department of Hematology and Oncology, Beijing Children's Hospital, Capital Medical University, 56 Nanlishi Road, Beijing 100045, P.R. China

E-mail: wangtydoc@163.com

Key words: hemophagocytic lymphohistiocytosis, infectious mononucleosis, angioimmunoblastic T cell lymphoma, drug eruption hematological disorder (1). The occurrence rate of HLH in adults is not well known (1). Despite this, epidemiology data collected from tertiary medical centers has indicated that the incidence rate is 1 out of every 2,000 adults (2). However, reported incidence of HLH in children varies among different studies, which may reflect a different prevalence within various ethnic groups (3-5). For example, HLH has been reported to have an incidence of 0.12 per 100,000 children per year in Sweden, with a male to female ratio of 1:1 (4), whereas it was found to be 0.342 per 100,000 in Japan, with a male to female ratio of $0.8: 1$ (5). HLH is caused by the uncontrolled proliferation and activation of lymphocytes and macrophages (1). It is classified as either familial/primary or acquired/secondary HLH (1). Secondary HLH may be associated with malignancy, viral infection or autoimmune conditions (1). The current therapeutic strategy involves the use of immunosuppressive agents; however, current literature indicates that the mortality rate of patients with secondary HLH is $50-75 \%$ (6). Atypical rashes may present in certain patients with HLH; however, to the best of our knowledge annular erythema multiforme-like eruptions have not previously been reported in cases of HLH. Herein, the case of a patient who acquired infectious mononucleosis (IM) and angioimmunoblastic T cell lymphoma (AITL)-associated HLH at the same time as annular erythema multiforme-like eruptions is reported. There are three previously reported cases of AITL-associated HLH (7-9), but these were not accompanied by annular erythema multiforme-like eruptions. This was a rare case, and the patient was initially misdiagnosed with erythema multiforme and drug eruption. The patient was subsequently successfully diagnosed and treated.

\section{Case report}

A 53-year-old male patient, who was diagnosed with rectal carcinoma and had undergone chemotherapy following proctectomy for 1 year, suffered from cough and submandibular lymphadenopathy 9 days prior to admitting to the Dermatology Department of Beijing Chao-Yang Hospital (Beijing, China) with swelling and slight pain but no fever. The patient was diagnosed with acute tonsillitis by otolaryngologists and was initially treated with oral cefuroxime axetil tablets (dosage 
not documented). However, treatment was stopped following taking the medicine for 4 days due to the condition not entering remission. Annular erythema and maculopapular rashes or purpura were observed accompanied with pruritus on the patient's legs 7 days prior to admission to the ward (Fig. 1A) Similar lesions appeared on the patient's chest (Fig. 1B) and back (Fig. 1C) at 4 days prior to admission without fever. Complete blood cell count was normal, revealing a white blood cell count of $6.72 \times 10^{9} / 1$ (normal, 3.5-9.5 $\left.\times 10^{9} / 1\right)(10)$, monocyte count of $0.48 \times 10^{9} / 1$ (normal, $0.1-0.6 \times 10^{9} / 1$ ) (10), hemoglobin concentration of $13.7 \mathrm{~g} / \mathrm{dl}$ (normal, 13.0-17.5 g/dl) (10) and platelet count of 213.0x10 $/ 1$ (normal, 125.0-350.0x10 $/ 1$ ) (10). Initially, the patient was diagnosed with erythema multiforme and drug eruption. In primary care, he was treated with oral prednisolone, antihistamine and steroid ointment.

Consequently, the rashes did not disappear and fever developed on the third day with temperature fluctuating between 36.3 and $39.0^{\circ} \mathrm{C}$ in the ward. Physical examination detected superficial lymphadenopathy (size, $<1 \times 1 \mathrm{~cm}$ ). Diffuse membranous tonsillitis appeared and spots of small hemorrhage also appeared on the hard and soft palates and the connection between the hard and soft palates (Fig. 1D). Blood cell count revealed that monocyte content increased when compared with levels at admission, with a white blood cell count of $8.35 \times 10^{9} / 1$, monocyte count of $1.02 \times 10^{9} / 1$, hemoglobin concentration of $13.0 \mathrm{~g} / \mathrm{dl}$ and platelet count of $211.0 \times 10^{9} / 1$. Notably, a population of medium-sized morphologically atypical lymphocytes in the blood accounted for $9 \%$ of all lymphocytes. The concentrations of liver enzymes were slightly increased compared with normal ranges; the concentration of alanine aminotransferase was $52 \mathrm{U} / 1$ (normal, 9-50 U/l) (11) and of aspartate aminotransferase was $30 \mathrm{U} / 1$ (normal, 15-40 U/1) (11). The level of triglyceride was normal. Antinuclear antibodies, anti-double-stranded DNA antibodies and rheumatoid factor were negative. The level of C-reactive protein was elevated $(3.96 \mathrm{mg} / \mathrm{dl}$; normal, $0-0.8 \mathrm{mg} / \mathrm{dl})(12)$, and the erythrocyte sedimentation rate was increased (43 mm/h; normal, 2-15 mm/h) (12). Epstein-Barr virus (EBV) DNA was detected in peripheral blood at a high copy number $\left(8.42 \times 10^{4} / 1\right.$ copies IU/ml; normal, $<5.0 \times 10^{2} / 1$ copies $\mathrm{IU} / \mathrm{ml}$ ) by quantitative polymerase chain reaction (measured in hospital's molecular genetics department) (13). A serological examination (measured in hospital's molecular genetics department) (14) indicated that EBV immunoglobulin (Ig)G was positive and EBV IgM was negative. Other serologic profiles, including of EBV viral capsid antigen and nuclear antigen, were not examined in hospital. The patient refused skin biopsy, and abdominal ultrasound indicated splenomegaly. As a result, the patient was diagnosed with IM and was treated with ganciclovir and prednisone.

After 8 days, the rashes on the patients' limbs and torso diminished slightly following treatment. However, body temperature increased repeatedly (maximum, $39.5^{\circ} \mathrm{C}$ for $>7$ days) and sweating was experienced during the night. Furthermore, the size of supraclavicular lymph nodes increased $(>1 \times 1 \mathrm{~cm})$. Computed tomography scans confirmed hepatosplenomegaly and lymphadenopathy of multiple nodes in the abdominal, pelvic cavity, retroperitoneal and the inguinal regions. In addition, blood cell count as aforementioned, revealed that hemoglobin concentration and platelet count in the patient continued to decline progressively, with a hemoglobin concentration of
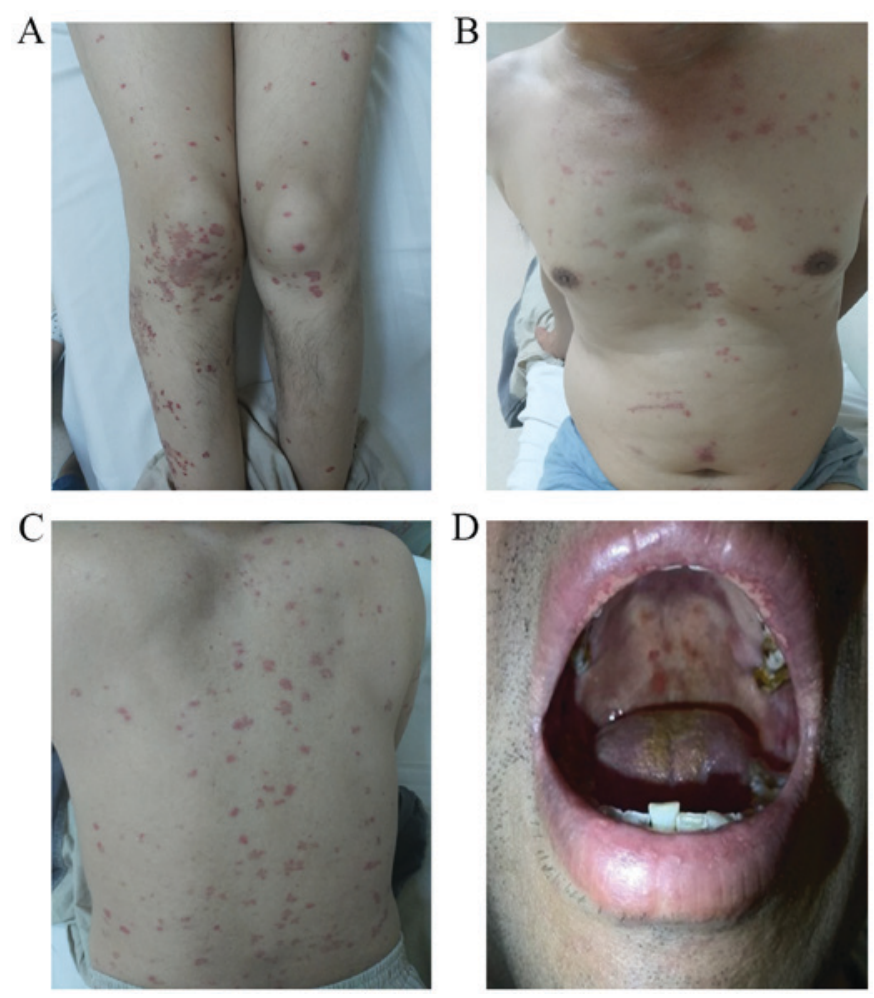

Figure 1. Clinical characteristics of the patient. Lesions were observed on the (A) legs, (B) chest and (C) back presented as red maculopapular or purpuric rash, or ecchymosis. (D) Bleeding spots also appeared on the upper jaw.

$11.6 \mathrm{~g} / \mathrm{dl}$ and a minimum platelet count of $37.0 \times 10^{9} / 1$ with $10 \%$ atypical lymphocytes. Serum ferritin and lactate dehydrogenase levels were $785.80 \mathrm{ng} / \mathrm{ml}$ and $370 \mathrm{U} / 1$, respectively. The level of EBV DNA increased to $6.0 \times 10^{5} / 1$ copies IU/ml. The coagulation profile revealed prothrombin time of $3.4 \mathrm{sec}$ (normal, 9.6-13.0 sec), activated partial thromboplastin time of $41.2 \mathrm{sec}$ (normal, 21.0-34.0 sec) and fibrinogen of $240.8 \mathrm{mg} / \mathrm{dl}$ (normal, 170.0-400.0 mg/dl). A serological examination indicated the presence of polyclonal gammopathy with a value of 2,280 mg/dl for $\mathrm{IgG}$ (normal, 715-1,560 mg/dl), $677 \mathrm{mg} / \mathrm{dl}$ for IgM (normal, $82-453 \mathrm{mg} / \mathrm{dl}$ ) and 1,550 mg/dl for IgA (normal, 46-304 mg/dl). The bone marrow examination indicated hemophagocytosis and abnormal lymphocytes. The level of soluble cluster of differentiation (CD) 25 was increased $(>44,000 \mathrm{pg} / \mathrm{ml}$; normal $<6,400 \mathrm{pg} / \mathrm{ml}$; test result from Beijing Friendship Hospital, Beijing, China) (15), and natural killer (NK) cell activity was normal (25.38\%; normal $\geqq 15.11 \%$; test result from Beijing Friendship Hospital, Beijing, China) (16). Therefore, there was a clear indication of HLH. The patient was subsequently treated with ganciclovir, dexamethasone and etoposide. At 1 day following chemotherapy, the platelet count increased to $63 \times 10^{9} / 1$ and the patient exhibited a normal temperature.

Simultaneously, biopsies of the left cervical lymph node indicated the disappearance of normal structure, infiltration of eosinophil cells and small to medium-sized lymphoid cells in the extra membrane and vascular proliferation (Fig. 2A and B). The immunohistochemical staining of lymphoid infiltrates indicated diffuse positive staining for CD2, CD3, CD5, CD7 and CD10 as well as weak positive staining for CD20, paired-box domain 5 and telomerase B (17). The staining for CD21 suggested damage of follicular dendritic cells and a 

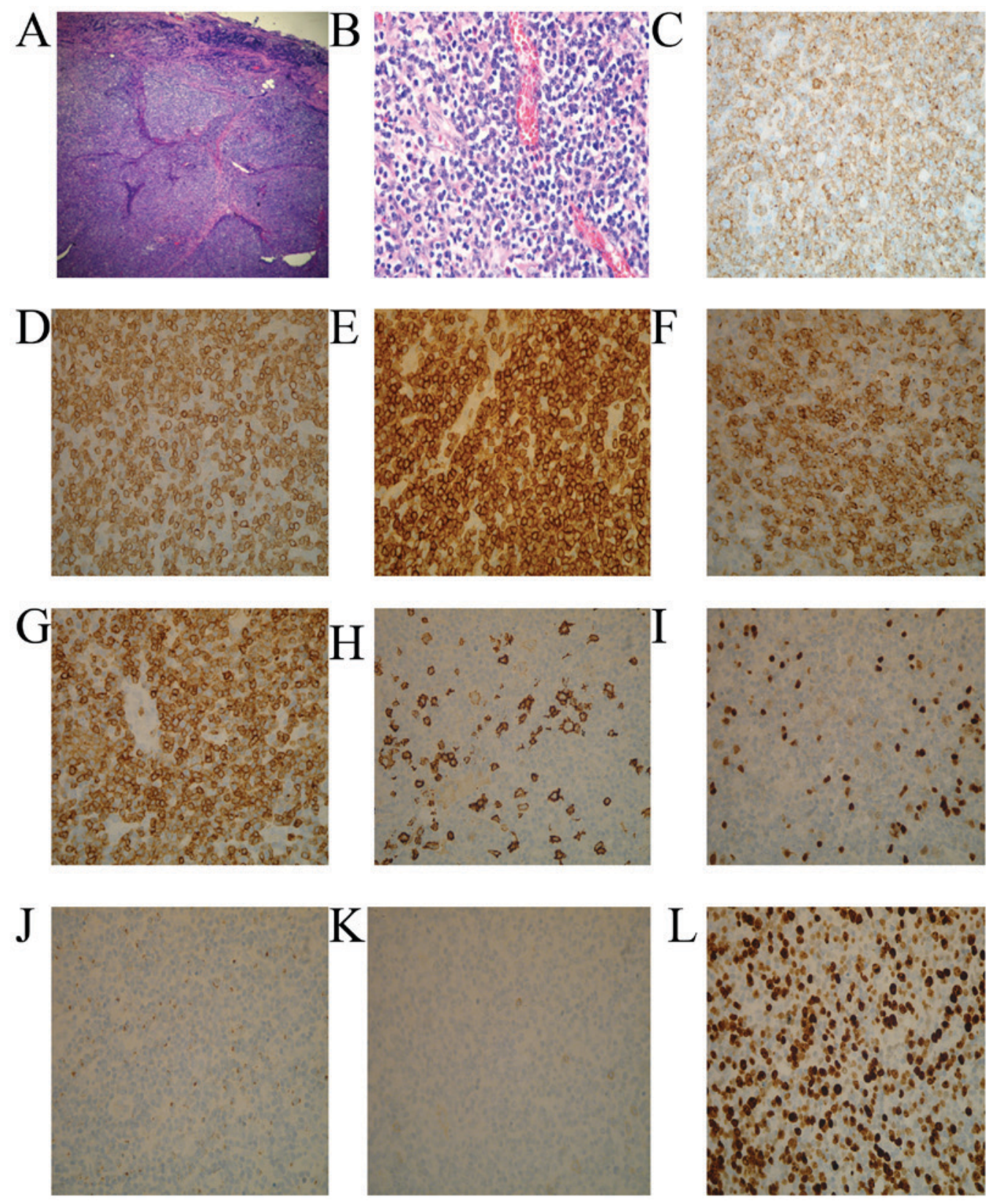

Figure 2. Histological and immunohistochemical staining findings of the patient. A biopsy sample taken from the left cervical lymph node revealed that normal structure had disappeared, and small to medium-sized atypical lymphoid cells had infiltrated the lymph node region. (A) H\&E staining; original magnification, x10. (B) H\&E staining; original magnification, x40. (C-G) On immunohistochemical staining, the lymphoid cells were diffusely positive for CD2, CD3, CD5, CD7 and CD10 (H\&E staining; original magnification, x40). (H) CD20, (I) paired-box domain 5 and (J) telomerase B staining were weak positive (H\&E staining; original magnification, $\mathrm{x} 40$ ). (K) CD21 staining suggested follicular dendritic cells net damage (H\&E staining; original magnification, $\mathrm{x} 40$ ). (L) Proliferative index with Ki-67 stain was high (H\&E staining; original magnification, $\mathrm{x} 40$ ). $\mathrm{H} \& \mathrm{E}$, hematoxylin and eosin; CD, cluster of differentiation.

high expression of Ki-67 (Fig. 2C-L) (17). EBV-encoded RNA in-situ hybridization (EBER) revealed that the tumor cells were positive for EBV (18). Therefore, there was a clear indication of AITL. Consequently, the patient was treated with etoposide together with cyclophosphamide, doxorubicin, vincristine and prednisolone (CHOP regimen). The patient was successfully treated with several courses of chemotherapy, and clinical manifestations improved. The rashes faded away completely. The patient was followed up once every 2 weeks for 3 months and he was deemed to be in good condition.

Test results, including EBV DNA qPCR, lymph node biopsies and EBER, were collected from professional clinical laboratory technicians and professional pathologists from
Beijing Chao-Yang Hospital (Beijing, China). To perform qPCR patient DNA was extracted. Blood was collected into EDTA-coated tubes and isolated manually using the QIAamp Blood Mini kit (Qiagen Inc., Valencia, CA). Quantitative PCR was then performed using a TaqMan PCR Core Reagent kit (PerkinElmer, Inc., Waltham, MA, USA). In this system, a dual-labeled fluorogenic hybridization probe was included. DNA samples were quantified for EBV DNA using a real-time qPCR system targeting the Bam HI-W fragment region of the EBV genome (19). The BamHI-W system utilized the following primers: W- 44 forward, 5'-CCCAACACTCCACCACACC-3' and reverse, W-119 5'-TCTTAGGAGCTGTCCGAGGG-3'. GAPDH was used 
Table I. List of reported patients with angioimmunoblastic T cell lymphoma associated with Hemophagocytic lymphohistiocytosis, clinical manifestation, treatment, and outcomes.

\begin{tabular}{|c|c|c|c|c|}
\hline Age, years/sex & Clinical manifestation & Therapy & Outcome & Reference \\
\hline $58 / \mathrm{F}$ & $\begin{array}{l}\text { Fever, pharyngeal pain, } \\
\text { lymphadenopathy, } \\
\text { splenomegaly }\end{array}$ & $\begin{array}{l}\text { CHOP, fludarabine, cyclosporine } \mathrm{A}, \\
\text { allogeneic peripheral blood stem cell } \\
\text { transplantation }\end{array}$ & Successfully treated & 7 \\
\hline $57 / \mathrm{M}$ & $\begin{array}{l}\text { Fever, neutropenia, } \\
\text { thrombocytopenia, } \\
\text { lymphadenopathy }\end{array}$ & $\begin{array}{l}\text { Cyclophosphamide, prednisolone, } \\
\text { etoposide, cicloporin }\end{array}$ & $\begin{array}{l}\text { Succumbed to } \\
\text { multiorgan failure }\end{array}$ & 8 \\
\hline $62 / \mathrm{F}$ & $\begin{array}{l}\text { Fever, lymphadenopathy, } \\
\text { hepatosplenomegaly, } \\
\text { loss of weight }\end{array}$ & $\begin{array}{l}\text { CHOP, mesna, ifosfamide, mitoxantrone, } \\
\text { etoposide; allogeneic hematopoietic stem } \\
\text { cell transplantation }\end{array}$ & Successfully treated & 9 \\
\hline
\end{tabular}

F, female; M, male; CHOP, Cyclophosphamide, doxorubicin, vincristine, and prednisolone.

as the internal reference gene (forward, 5'-GTCTTCACC ACCATGGAGAAGGCT-3' and reverse, 5'-CATGCCAGT GAGCTTCCCGTTCA-3'). The dual-labeled fluorescent probe W-67T [5'-(fluorescent reporter) CACACACTACAC ACACCCACCCGTCTC (TAMRA fluorescent dye)-3'; PerkinElmer, Inc.] (19). Primer/probe combinations were designed using Primer Express software (PerkinElmer, Inc.). Fluorescent probes were custom-synthesized by PerkinElmer, Inc. PCR primers were synthesized by Thermo Fisher Scientific, Inc. (Waltham, MA, USA). The thermocycling conditions were as follows: Initial denaturation for $10 \mathrm{~min}$ at $95^{\circ} \mathrm{C} ; 40$ cycles at $95^{\circ} \mathrm{C}$ for $15 \mathrm{sec}, 56^{\circ} \mathrm{C}$ for $1 \mathrm{~min}$ and $72^{\circ} \mathrm{C}$ for $45 \mathrm{sec}$. Sequence data for the EBV genome were obtained from the GenBank Sequence Database (https://www.ncbi.nlm. nih.gov/nuccore/V01555) (13). PCR assays were performed in triplicate. The following quantitative PCR detector systems were used: STF-Rotor-gene Q (Qiagen, Inc.), 7700 Sequence Detector (Apple, Inc., Cupertino, CA), and the sequence detection system software (version 1.7) was developed by PerkinElmer, Inc (13). Pathological biopsies were fixed at room temperature for $6 \mathrm{~h}$ using $10 \%$ formalin, dehydrated, embedded in paraffin, sectioned (thickness, 3-5 $\mu \mathrm{m}$ ), de-waxed and stained with hematoxylin at room temperature for 5-15 min and eosin at room temperature for 2-3 $\mathrm{min}$ as previously described (17). Reagents were from OriGene Technologies, Inc. (Rockville, MD, USA). Like immunohistochemical staining, the protocols were as follows: De-waxing, antigen repair using Histostain ${ }^{\mathrm{TM}}$-SP kits (OriGene Technologies, Inc.) and antibody incubation. The antibodies utilized included: with CD2 (cat. no. UMAB86), CD3 (cat. no. UM570048), CD5 (cat. no. UM570009), CD7 (cat. no. TA506337), CD10 (cat. no. TA590055), CD20 (cat. no. UM800065), CD21 (cat. no. TA327627) and Ki-67 (TA801577) all diluted at 1:100. paired-box domain 5 (cat. no. TA801884) and telomerase B (cat. no. TA301588) were diluted at 1:50 (all antibodies were obtained from OriGene Technologies, Inc.) and hematoxylin staining as previously described (17). EBV-encoded RNA in-situ hybridization involved sample de-waxing, proteinase $\mathrm{K}$ digestion $\left(25 \mu \mathrm{g} / \mathrm{ml}, 37^{\circ} \mathrm{C}\right.$ for $10 \mathrm{~min}$; Merck $\mathrm{KGaA}$, Darmstadt, Germany). Oligonucleotide probes (5'-CTCCTC CCTAGCAAAACCCTCAGGACGGCG-3' from OriGene
Technologies, Inc. were labeled using a Labeling kit (Boehringer Mannheim, S.A., Barcelona, Spain). Labeled probes were diluted to a concentration of $0.1 \mu \mathrm{g} / \mathrm{ml}$ in hybridisation medium $(50 \%$ formamide, $5 \%$ dextran sulphate, $2 \mathrm{x}$ sodium citrate, sodium chloride (SSC); all provided by the EBER hybridization kit, OriGene Technologies, Inc.). Diluted probes were spotted onto tissue sections and a coverslip was placed on top. Diaminobenzidine tetrahydrochloride (as obtained from the EBER hybridization kit) was used as the chromogen (18). Hybridisation signals were detected using a three layer ABC-peroxidase technique (Vector Laboratories, Ltd., Peterborough, UK) (20).

\section{Discussion}

HLH is a rare and life-threatening disease, which is characterized by cytokine storms (1). This hyper-inflammatory reaction can cause damage to multiple organ systems (1). The causes of mortality in HLH include multiple organ dysfunction syndrome, massive hemorrhaging and infectious disease (21).

HLH can be divided into primary (genetic) and secondary (acquired) HLH. Gene mutations in perforin 1, Unc-13 Homolog $\mathrm{D}$, syntaxin 11 and syntaxin binding protein 2 can result in damaged cytotoxic function of NK and cytotoxic T cells (1). Primary HLH often occurs in children (22). However, it has been demonstrated to also occur in adolescents and adults (22). Infection is a common cause of secondary HLH, particularly EBV infections (1). Of note, hormones and antiviral treatments are often effective against acute EBV infections (1). Secondary $\mathrm{HLH}$, which is triggered by tumors, typically occurs in adults ( $45 \%$ of cases) (23). AITL, a type of T-cell non-Hodgkin's lymphoma, is frequently accompanied by progressive systemic symptoms, including high fever, cytopenia, body weight loss and night sweats $(24,25)$. AITL, unlike other T cell lymphomas, can be associated with a profound immune deficiency that is caused by chemotherapy or immunotherapy, which leads to the activation of EBV (26). In particular, EBV infections have been reported predominantly in patients with AITL (27). Zhou et al (28) previously reported that EBV infections, as a consequence of AITL, may be reactivated in the presence of immunodeficiency rather than contributing to the pathogenesis 
of the disease itself (28). AITL-associated HLH has a poor prognosis due to continuous disease aggravation, which leads to an increased risk for opportunistic infections compared with EBV-associated HLH (29). The present case demonstrated that AITL was the cause for triggering HLH. Due to immune deficiency that was induced by rectal carcinoma chemotherapy, the EBV infection in the patient was activated. There are three previously reported cases of AITL-associated HLH (Table I) (7-9).

Skin manifestations occur in $24-40 \%$ cases of genetic HLH and $6-65 \%$ of cases in acquired HLH (28). Reported cutaneous findings have included erythematous rashes, macules, edema, panniculitis, morbilliform erythema, petechiae and purpura $(30,31)$. The lesions in HLH are not characteristic; the most common cutaneous manifestations are panniculitis and purpura $(32,33)$. Cutaneous manifestations that are associated with HLH are classified into three types. The manifestation may be specific to the underlying malignancy (cutaneous lymphoma or systemic disease), reflect the biological consequences of HLH (thrombopenic purpura or conjunctival jaundice) or can be a generalized, transient, nonpruritic, maculopapular rash (34). However, a case with AITL-associated HLH and annular erythema multiforme-like eruptions has not been previously reported, to the best of our knowledge.

The occurrence of AITL-associated HLH with annular erythema multiforme-like eruptions in a patient is highly rare worldwide, which led to the misdiagnosis of erythema multiforme. From this patient and the other 3 reported patients with AITL-associated HLH, it was observed that AITL-associated HLH occurred in people with an age of $>50$ years. CHOP and etoposide combined with allogeneic hematopoietic stem cell transplantation may be effective in the early stages of the disease.

In conclusion, this present case of AITL-associated HLH with annular erythema multiforme-like rashes provides novel understanding for clinical diagnosis of the disease. Without rapid diagnosis and early treatment, AITL-associated HLH may lead to short survival times.

\section{Acknowledgements}

Not applicable.

\section{Funding}

The present study was supported by the National Science and Technology Key Projects (grant no. 2017ZX09304029004), China.

\section{Availability of data and materials}

The datasets used and/or analyzed during the current study are available from the corresponding author on reasonable request.

\section{Authors' contributions}

LZ, CT and YH designed the present study and drafted the manuscript. YT, SP and LZ collected the clinical and imaging data. TW analyzed and interpreted the patient data regarding the hematological disease. CT and LZ were major contributors in writing and revising the manuscript. All authors read and approved the final manuscript.

\section{Ethics approval and consent to participate}

The patient provided informed written consent for their participation.

\section{Patient consent for publication}

The patient provided informed written consent.

\section{Competing interests}

The authors declare that they have no competing interests.

\section{References}

1. Al-Samkari H and Berliner N: Hemophagocytic lymphohistiocytosis. Annu Rev Pathol 13: 27-49, 2018.

2. Parikh SA, Kapoor P, Letendre L, Kumar S and Wolanskyj AP: Prognostic factors and outcomes of adults with hemophagocytic lymphohistiocytosis. Mayo Clin Proc 89: 484-492, 2014.

3. Gholam C, Grigoriadou S, Gilmour KC and Gaspar HB: Familial haemophagocytic lymphohistiocytosis: Advances in the genetic basis, diagnosis and management. Clin Exp Immunol 163: 271-283, 2011.

4. Henter JI, Elinder G, Soder O and Ost A: Incidence in Sweden and clinical features of familial hemophagocytic lymphohistiocytosis. Acta Paediatr Scand 80: 428-435, 1991.

5. Ishii E, Ohga S, Tanimura M, Imashuku S, Sako M, Mizutani S and Miyazaki S: Clinical and epidemiologic studies of familial hemophagocytic lymphohistiocytosis in Japan. Med Pediatr Oncol 30: 276-283, 1998.

6. Schram AM and Berliner N: How I treat hemophagocytic lymphohistiocytosis in the adult patient. Blood 125: 2908-2914, 2015.

7. Matsumura Y, Kuroda J, Shimura Y, Kiyota M, Yamamoto-Sugitani M, Kobayashi T, Matsumoto Y, Horiike S and Taniwaki M: Cyclosporine a and reduced-intensity conditioning allogeneic stem cell transplantation for relapsed angioimmunoblastic t cell lymphoma with hemophagocytic syndrome. Intern Med 51: 2785-2787, 2012.

8. Vella JE and El-Daly H: Hemophagocytic lymphohistiocytosis in a patient with angioimmunoblastic lymphoma: A case report and review of the literature. Int J Surg Pathol 20: 606-609, 2012.

9. Yu JT, Hwang WL, Wang RC and Teng CL: Reduced intensity conditioning allogeneic hematopoietic stem cell transplant could be beneficial to angioimmunoblastic T-cell lymphoma patients with hemophagocytic lymphohistiocytosis. Ann Hematol 91: 805-807, 2012.

10. Wu X, Zhao M, Pan B, Zhang J, Peng M, Wang L, Hao X, Huang X, Mu R, Guo W, et al: Complete blood count reference intervals for healthy Han Chinese adults. PLoS One 10: e0119669, 2015.

11. Shinya S, Masaru A, Akira H, Eisaku H and Susumu O: Development of an assay of seven biochemical items, HbA1c, and hematocrit using a small amount of blood collected from the fingertip. Clin Chim Acta 413: 192-197, 2012.

12. Crowson CS, Rahman MU and Matteson EL: Which measure of inflammation to use? A comparison of erythrocyte sedimentation rate and C-reactive protein measurements from randomized clinical trials of golimumab in rheumatoid arthritis. J Rheumatol 36: 1606-1610, 2009

13. Lo YM, Chan LY, Lo KW, Leung SF, Zhang J, Chan AT, Lee JC, Hjelm NM, Johnson PJ and Huang DP: Quantitative analysis of cell-free Epstein-Barr virus DNA in plasma of patients with nasopharyngeal carcinoma. Cancer Res 59: 1188-1191, 1999.

14. Gu AD, Mo HY, Xie YB, Peng RJ, Bei JX, Peng J, Li MY, Chen LZ, Feng QS, Jia WH and Zeng YX: Evaluation of a multianalyte profiling assay and an enzyme-linked immunosorbent assay for serological examination of Epstein-Barr virus-specific antibody responses in diagnosis of nasopharyngeal carcinoma. Clin Vaccine Immunol 15: 1684-1688, 2005. 
15. Oboshi W, Aki K, Tada T, Watanabe T, Yukimasa N, Ueno I, Saito K and Hosoi E: Flow cytometric evaluation of surface CD56 expression on activated natural killer cells as functional marker. J Med Invest 63: 199-203, 2016.

16. Valiathan R, Lewis JE, Melillo AB, Leonard S, Ali KH and Asthana D: Evaluation of a flow cytometry-based assay for natural killer cell activity in clinical settings. Scand J Immunol 75: 455-462, 2012.

17. Zu Y, Steinberg SM, Campo E, Hans CP, Weisenburger DD, Braziel RM, Delabie J, Gascoyne RD, Muller-Hermlink K, Pittaluga S, et al: Validation of tissue microarray immunohistochemistry staining and interpretation in diffuse large B-cell lymphoma. Leuk Lymphoma 46: 693-701, 2005.

18. Wang Y, Liu X and Chen Y: Adult systemic Epstein-Barr virus-positive T-cell lymphoproliferative disease: A case report. Exp Ther Med 10: 1025-1028, 2015.

19. Baer R, Bankier AT, Biggin MD, Deininger PL, Farrell PJ, Gibson TJ, Hatfull G, Hudson GS, Satchwell SC, Séguin C, et al: DNA sequence and expression of the B95-8 Epstein-Barr virus genome. Nature 310: 207-211, 1984.

20. Khan G, Coates PJ, Kangro HO and Slavin G: Epstein Barr virus (EBV) encoded small RNAs: Targets for detection by in situ hybridisation with oligonucleotide probes. J Clin Pathol 45 616-620, 1992.

21. Smith KJ, Skelton HG III, Giblin WL and James WD: Cutaneous lesions of hemophagocytic syndrome in a patient with T-cell lymphoma and active Epstein-Barr infection. J Am Acad Dermatol 25: 919-924, 1991.

22. Jordan MB, Allen CE, Weitzman S, Filipovich AH and McClain KL: How I treat hemophagocytic lymphohistiocytosis. Blood 118: 4041-4052, 2011.

23. Allen CE and McClain KL: Pathophysiology and epidemiology of hemophagocytic lymphohistiocytosis. Hematology Am Soc Hematol Educ Program 2015: 177-182, 2015.

24. Takahashi N, Chubachi A, Kume M, Hatano Y, Komatsuda A, Kawabata Y, Yanagiya N, Ichikawa Y, Miura AB and Miura I: A clinical analysis of 52 adult patients with hemophagocytic syndrome: The prognostic significance of the underlying diseases. Int J Hematol 74: 209-213, 2001

25. Koh MJ, Sadarangani SP, Chan YC, Chan MY, Tan AM, Tan SH, Tay YK and Ng SB: Aggressive subcutaneous panniculitis-like T-cell lymphoma with hemophagocytosis in two children (subcutaneous panniculitis-like T-cell lymphoma). J Am Acad Dermatol 61: 875-881, 2009.
26. Castillo JJ, Beltran BE, Bibas M, Bower M, Collins JA, Cwynarski K, Diez-Martin JL, Hernandez-Ilizaliturri F, Horwitz SM, Montoto S, et al: Prognostic factors in patients with HIV-associated peripheral T-cell lymphoma: A multicenter study. Am J Hematol 86: 256-261, 2011.

27. Zettl A, Lee SS, Rüdiger T, Starostik P, Marino M, Kirchner T, Ott M, Müller-Hermelink HK and Ott G: Epstein-Barr virus-associated B-Cell lymphoproliferative disorders in angioimmunoblastic T-cell lymphoma and peripheral T cell lymphoma, unspecified. Am J Clin Pathol 117: 368-379, 2002.

28. Zhou Y, Attygalle AD, Chuang SS, Diss T, Ye H, Liu H, Hamoudi RA, Munson P, Bacon CM, Dogan A and Du MQ: Angioimmunoblastic T-cell lymphoma: Histological progression associates with EBV and HHV6B viral load. Br J Haematol 138: 44-53, 2007.

29. Brown HA, Macon WR, Kurtin PJ and Gibson LE: Cutaneous involvement by angioimmunoblastic T-cell lymphoma with remarkable heterogeneous Epstein-Barr virus expression. J Cutan Pathol 28: 432-438, 2001.

30. Zerah ML and DeWitt CA: Cutaneous findings in hemophagocytic lymphohistiocytosis. Dermatology 230: 234-243, 2015.

31. Ariffin H, Lum SH, Cheok SA, Shekhar K, Ariffin WA, Chan LL and Lin HP: Haemophagocytic lymphohistiocytosis in Malaysian children. J Paediatr Child Health 41: 136-139, 2005.

32. Smith KJ, Skelton HG, Yeager J, Angritt P, Wagner K, James WD, Giblin WJ and Lupton GP: Cutaneous histopathologic, immunohistochemical, and clinical manifestations inpatients with hemophagocytic syndrome. Military medical consortium for applied retroviral research (MMCARR). Arch Dermatol 128: 193-200, 1992.

33. Sakai H, Otsubo S, Miura T and Iizuka H: Hemophagocytic syndrome presenting with a facial erythema in a patient with systemic lupus erythematosus. J Am Acad Dermatol 57: S111-S114, 2007

34. Fardet L, Galicier L, Vignon-Pennamen MD, Regnier S, Noguera ME, de Labarthe A, Raffoux E, Martinez V, Buyse S, Viguier M, et al: Frequency, clinicalfeatures and prognosis of cutaneous manifestations in adult patients with reactive haemophagocytic syndrome. Br J Dermatol 162: 547-553, 2010. 